\title{
INTRASEXUAL AGGRESSION IN THE STICK INSECTS DIAPHEROMERA VELIEI AND D. COVILLEAE AND SEXUAL DIMORPHISM IN THE PHASMATODEA*
}

\author{
By JoHN SIVINSKI \\ Department of Entomology and Nematology \\ University of Florida \\ Gainesville, Florida 32611
}

\section{INTRODUCTION}

Pairing ${ }^{1}$ in the Phasmatodea is notable for its duration. The Indian stick insect Necroscia sparaxes may remain coupled for up to 79 days (a record for insects) and accounts of matings lasting days or weeks are commonplace (LeFeuvre 1939; Korboot 1961; Gangrade 1963; Gustafson 1966; Clark 1974). Intromission may occur only initially or intermittently. In either case, a substantial proportion of male time-investment is not spent in ejaculate transfer. In captivity, Diapheromera veliei and D. covilleae pair for 3 to 136 hours and the penis may be inserted and removed up to 9 times. The genitalia are not in contact for ca. $40 \%$ of this period, and attachment is maintained by a male clasping organ.

According to the best current explanation, males remain with females when not actively engaged in insemination to guard against the introduction of rival ejaculates and so avoid sperm competition (the competition of sperm from 2 or more males for the fertilization of an ovum; Parker 1971, 1974). Male aggression for possession of mating females has been described in a variety of insects (Parker 1970). In the only account known to me of attempted mate theft by a stick insect, an intruding male Orxines macklotti made several futile efforts to engage his genitalia, climbed off and walked away (Robinson 1965). Also indicative of a passive defense was a congregation of Carausius alluaudi collected in the Seychelles Islands consisting of 6 males clasping a female's abdomen at various points (a seventh male was nearby) (Bolivar and Ferriero 1912). While sedentary guarding of the female might be typical, lack of any

*Manuscript received by the editor January 27, 1979.

The vocabulary describing attachment between male and female is often inadequate for insects. In this paper mating, coupling, and pairing imply continuous attachment and not constant intromission. 
observed aggression may result from a paucity of observers, a consequence of the Phasmatodea being ". . . less studied than any other order of the Orthopteroidea . .." (Bradley and Galil 1977).

This paper describes conflict between males in the walkingsticks Diapheromera veliei and D. covilleae. Results of an experiment are presented relating male size to ability to monopolize females. Data on sex-related size-dimorphism in the 2 species are compared to published values for other members of the order to reach tentative correlations between population structure, mating strategies and the relative size of males.

\section{MATERiALS}

Adult Diapheromera veliei were obtained in Bernalillo Co., New Mexico, from the legume Dalea scoparia, and specimens of $D$. covilleae from creosote bush (Larrea tridentata) in Dona Ana Co., New Mexico. Observations were made on insects contained with the appropriate host plant in 10-gallon aquaria. Densities within aquaria varied from 3 to 10 adults. These densities, while high, were not unnatural. Up to 7 adult males and a single female have been found on a bush whose greatest dimension was 1.5 meters. Insects are often unevenly distributed in nature, and it was not unusual to see several adult males within $30 \mathrm{~cm}$. of a mating pair.

The effect of size on the ability of male $D$. veliei to maintain attachment to females was examined by keeping a small $(\bar{x}=67$ $\mathrm{mm}$.) and a large ( $\overline{\mathrm{x}}=87 \mathrm{~mm}$.) male with a female in each of ten 10gallon aquaria. Tandem duration was recorded by checks at 2-hour intervals between 8:00 A.M. and 8:00 P.M.

To determine the distribution of sexual size-dimorphism within the Phasmatodea, body lengths of 155 species were obtained and a male-over-female ratio calculated for each (data from material deposited in the Florida State Collection of Arthropods, Gainesville, Florida; random selections in Brunner Von Wattenwyl and Redtenbacker 1908; the whole of the relevant material in Leigh 1909; Hebard 1923; Rehn and Rehn 1939; Gurney 1947; Salmon 1955; Korboot 1961; Bedford and Chinnick 1966; Gustafson 1966; Stroheker 1966; Paine 1968; Moxey 1971; Clark 1974). Many of the specimens were dried, and the possibility of differential shrinkage of the sexes was examined with specimens of $D$. veliei. Shrinkage in both sexes was 0 to $3 \%$ of live length after a drying period of 2 weeks. The sexual dimorphism of $D$. veliei and $D$. 
covilleae was determined by measurement of freshly killed specimens ( $D$. veliei - 48 males and 34 females; $D$. covilleae -20 males and 19 females).

\section{RESUlTS AND DiscusSiON}

Mating in both species is initiated by the male mounting the female dorsally and gripping her body and legs with his tarsi. Females seldom attempted to dislodge a suitor, and were never successful. The male abdomen curves underneath the female and his clasping organ attaches just anterior to the vulva (sometimes attachment is initially well above the vulva). The resulting position is typical of the order (Key 1970; Bedford 1978). Some male copulatory postures may aid in avoiding takeovers. Alexander's (1964) phylogenetic scheme of orthopteroid mating positions initiates with female above which then radiates to include a number of male above or end to end arrangements. These derived postures are conceivably more effective for male control of the area around the mating pair. In Diapheromera the dorsal position blocks the length of the female abdomen and facilitates additional means of preventing attachment by a second male.

At the approach of another walkingstick the consort almost invariably bends the tip of the female abdomen down upon itself with his clasping organ. The angle is sometimes sufficiently acute to bring the ventral surfaces of the female abdomen on both sides of the claspers into contact. A large part of the typical site of attachment is thereby denied to competitors. Less frequently, mating males strike out at approaching males with their forelegs.

Striking motions and manipulation of the abdomen are effective defenses and most attempts of intruding males to attach to a mating female were futile. Occasionally second males clasped the female abdomen and sometimes succeeded in inserting their genitalia into the vulva. This usually occurred when the consort was no longer in a dorsal position but had moved to the side of the female to feed. For periods of a few minutes to an hour, such "menages a trois" were maintained with incident. In 6 of over a score of double couplings and combats observed in $D$. veliei the entire sequence was recorded from approach of the second male to resolution of the competition. On one occasion the intruder left in less than an hour without harassment. In all other cases, fights occurred which followed a similar pattern. 
The males lean backwards, pulling at each other and often anchoring themselves by grasping foliage. Eventually, both become freely suspended, held only by their clasping organs. They then direct rapid sweeping blows against their opponent (Fig. 1). The forelegs are used in a boxing manner. After a few seconds to several minutes, one of the antagonists releases his grip and the victor shortly regains the dorsal position. Once attachment of the second male to the female is accomplished, takeover attempts are often successful. In the 5 fights in which the original male was known, he was displaced 3 times.

In $D$. veliei and $D$. covilleae, a spine is present on the mid femora of both sexes. Those of the male are enlarged and hooked. In $D$. covilleae combats, the opponent's thorax is held in the joint of the mid tibia and femur. By flexing the legs, the spine is brought against the body, and it was once seen to puncture the integument, drawing blood. Spines used in defense by stick insects are invariably more highly developed in males (Lea 1916; Robinson 1968; Bedford 1975) possibly because of their significance in male fighting.

Well-developed male clasping organs (as in Diapheromera spp.) are not universally present in the order. In reviewing the Australian Phasmatodea, Key (1970) found male cerci only occasionally modified into claspers. Perhaps varied cercal design is due to differing probabilities of takeover.

The mean male over female length ratio of a sample of 155 phasmid species (approximately $8 \%$ of described species) is .727 . The average male $D$. veliei is .922 of the mean female length. This is an unusually slight difference in body lengths (see Fig. 2), with $94 \%$ of the sample having relatively smaller males $(D$. covilleae has a similar male/female ratio: .916). It might be generally expected that males would be smaller than females when fecundity is dependent on size. By spending less time in development or consuming less food, males take fewer risks in reaching maturity. Even tiny males in species with internal fertilization are capable of producing an adequate ejaculate. Given that the niches of the sexes are similar, the degree of sexual dimorphism is apt to result from a balance of reproductive pressures acting on the male. These forces might include maximizing female encounter rates (mobility, material reserves affecting life span), the ability to invest materially in the success of progeny, and maintaining copulations by aggression. 


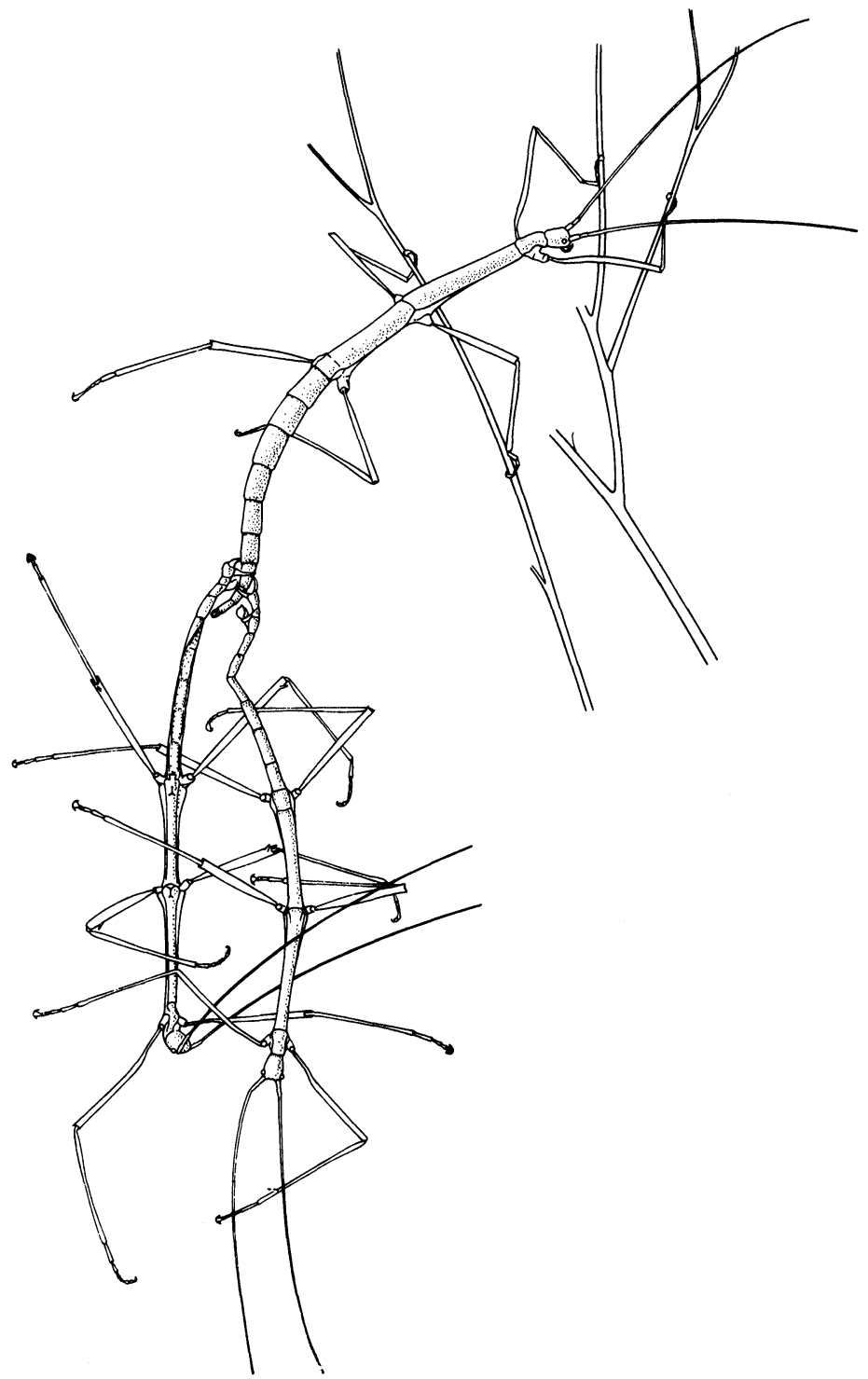

Figure 1. The combat of two male $D$. veliei both attached to a female by their clasping organs (drawing from $35 \mathrm{~mm}$ prints of captive specimens). 


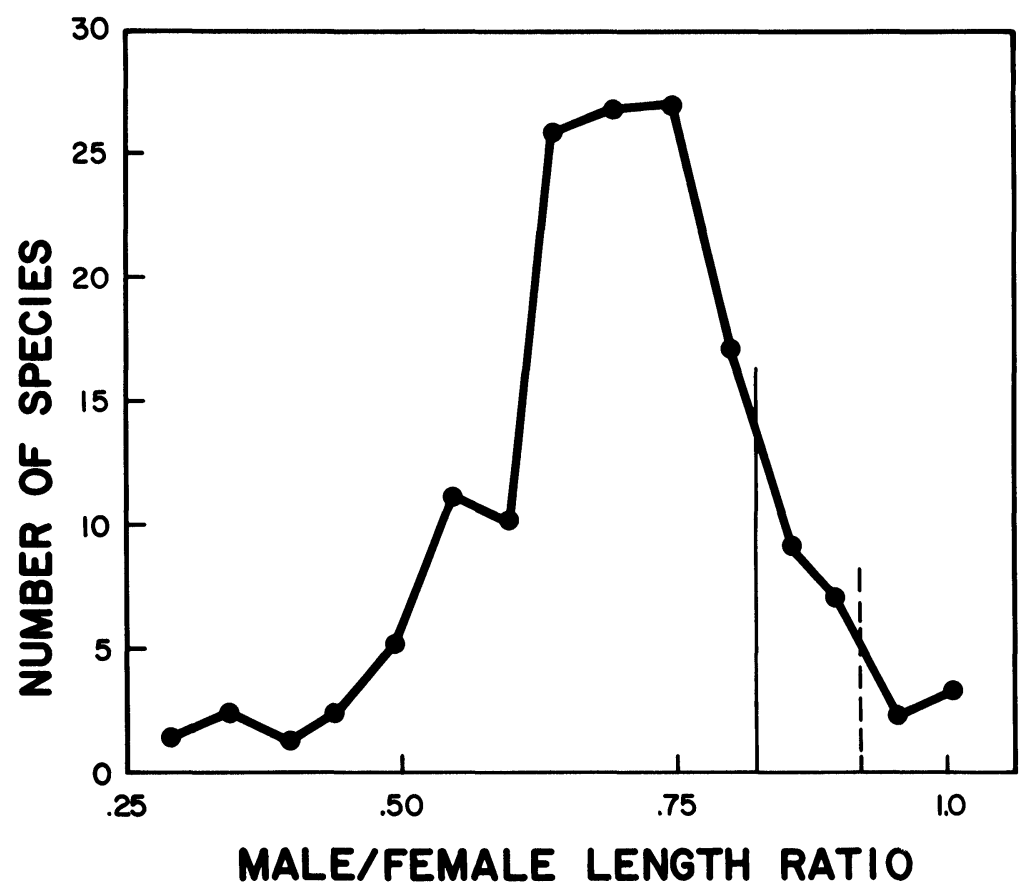

Figure 2. Male length/female length frequency distribution for the order Phasmatodea (generated from citations in materials section). Dots along the curve represent midpoints of categories spanning $5 \%$ on the male/female length axis and the number of species occupying these categories. The dashed vertical line represents the position of $D$. veliei (.922), the solid vertical line the mean dimorphism of high density species $(.814$, see text).

The positive relationship between copulatory success and size is well established for some polygynous vertebrates (citations in Trivers 1972). The great male bulk and armature of the dynastine scarab beetles are agonistic adaptations (Beebe 1944; Eberhard 1977). Larger males of the bibionid fly Plecia nearctica are more often found copulating than smaller males (Thornhill 1976). Potter et al (1976) showed size to be a critical factor in the outcome of combats between male mites.

In the 2 observed fights between male $D$. veliei of markedly disparate size, the larger won. Two males from the extremes of the size continuum were placed in 10 aquaria with single females and 924 hours of coupling were recorded. Large males accounted for 608 
hours $(62 \%)$. The difference in the mating durations between the size classes borders on significance $(.10>\mathrm{p}>.05)$.

Density and sex ratio are major components of the sexual environment and affect the extent of intrasexual competition (Parker 1974). Unlike the majority of walkingsticks, which are uncommon and widely dispersed (Key 1970; Craddock 1972), D. veliei and $D$. covilleae are locally abundant (as many as 22 individuals in a $1.5^{3}$ meter bush). Strongly male-biased adult sex ratios (up to 4:1) persist until late in the season, and are perhaps due to a combination of earlier male maturation and selective predation by birds during the early summer nesting period (Sivinski 1977).

In 9 other phasmids known to exist consistently or occasionally at high densities (numerous enough to cause defoliation of trees or at least 5 individuals occupying a bush or refuge), the mean male length/female length ratio is .814 (Wattenwyl and Redtenbacher 1908; Bedford 1975; Lea 1916; Gurney 1947; Wegner 1956; Stockard 1908; Hetrick 1949; Severin 1911; Key 1970; Paine 1968; Wilkins and Breland 1951). Over $3 / 4$ of the complete sample is more sexually dimorphic $(\mathrm{p}=.2201)$ (see Fig. 2). Kentromorphic phases, morphologically distinct forms existing at different densities, exist in several stick insects. As in locusts with density phases, dimorphism usually declines as populations reach their greatest concentrations (Key 1957; Uvarov 1966).

Individuals of Eurycantha spp. and Dryococelus australis are found in the closest spatial proximity of all known stick insects. Both congregate in tree hollows during the day (Gurney 1947). Aggregation sex ratios vary enormously and as many as 68 phasmids have been found in a single cavity (Lea 1916; Bedford 1975). Length dimorphism is minimal (.908) and males have massive hind femora studded with spines of sufficient magnitude to have been used as fishhooks (Balfour 1915).

Sexual dimorphism in some phasmids is exaggerated in comparison to other orthopteroid taxa. Species with below average dimorphism engage in the longest matings recorded in the order (Acrophylla tessellata, male/female $=.493$, duration 11 days, Korboot 1961; Anisomorpha buprestoides, .612, 3 weeks; Clark 1974; N. sparaxes, .700, 1-79 days, Gangrade 1963; Timema californica, .700, 5 weeks, Gustafson, 1966). Protracted couplings might contribute to selection for male diminution. Disruption of crypticity may be lessened and male maintenance cost kept to a 
minimum. Since the mating female bears much of the male's weight, a dwarfed male may be more fit in two additional contexts:

1) By allowing the female greater activity, the rate at which additional females are encountered is increased. A potentially polygynous male can search for mates while in copulo (blocking the female genitalia until the opportunity for another copulation arises). Mating durations in D. veliei are shorter when unmated females are present (Sivinski 1977). 2) By relieving the female's copulatory burden resources could be invested in ova the consort might fertilize. The longer the pairing the more likely this circumstance.

\section{SUMMARY}

Intrasexual combats, while common in the Orthopteroidea, have apparently not been previously recorded in the Phasmatodea. Fights between males in Diapheromera veliei and $D$. covilleae are described. The minimal sexual size-dimorphism of the two species in comparison to other walkingsticks may be due to a high level of intrasexual competition brought about by atypical population parameters (high density, male-biased sex ratios). It is suggested that extreme dimorphism in the order relieves the burden an attached male places upon female resources during lengthy copulations.

\section{ACKNOWLEDGEMENTS}

I would like to thank Randy Thornhill, James Lloyd, Thomas Walker, Bruce Woodward, and Pat Sivinski for their numerous criticisms and suggestions which led invariably to improvements. I am grateful to Joan Martin and Susan Wineriter for the illustrations.

\section{REFERENCES}

Alexander, R. D.

1964. The evolution of mating behavior in arthropods. Insect Reproduction Symposium No. 2, Roy. Ent. Soc. Lond. 78-94.

BALFOUR, $\mathrm{H}$.

1915. Note on a new kind of fishhook from Goodenough Island d'entrecasteaux group New Guinea. Man. 15: 171. 
BEDFORD, G. O.

1975. Defensive behavior of the New Guiana stick insect Eurycantha (Phasmatodea: Phasmatidea: Eurycanthinae). Proc. Linn. Soc. of New South Wales. 100(4): 218-221.

1978. Biology and ecology of the Phasmatodea. Ann. Rev. Entomol. 23: $125-49$.

Bedford, G. O., And L. J. Chinnick.

1966. Conspicuous displays in two species of Australian stick insects. Anim. Behav. 14: 518-521.

BEEBE, W.

1944. The function of secondary sexual characteristics in two species of Dynastinae (Coleoptera). Zoologica. 29(3): 53-58.

Bolivar, I., AND C. Ferriero.

1912. No. XVII Orthoptera, Phasmidae of the Seychelles. Trans. Linn. Soc. Lond. 15(2): 293-300.

Bradley, K. C., and B. S. Galil.

1977. The taxonomic arrangement of the Phasmatodea with keys to the subfamilies and tribes. Proc. Entomol. Soc. Wash. 79(2): 176-208.

BRUNNER VON WATTENWYl, K., AND J. ReDTENBACHER.

1908. Die insektenfamilie der phasmiden. Leipzig.

Clark, J. T.

1974. Stick and leaf insects. Barry Shurlock and Co., Winchester.

Craddock, E.

1972. Chromosomal diversity in the Australian Phasmatodea. Aust. J. Zool. 20: $445-462$.

EBerhard, W. G.

1977. Fighting behavior of male Golofa porteri beetles (Scarabeidae:Sp. Dynastinae). Psyche 84(3-4): 292-293.

GANGRADE, A.

1963. A contribution to the biology of Necroscia sparaxes Westwood (Phasmidae: Phasmida). The Entomologist. 96: 83-93.

GuRney, A. B.

1947. Notes on some remarkable Australian walkingsticks including a synopsis of the genus Extatosoma (Orthoptera: Phasmidae). Ann. Amer. Entomol. Soc. 59(1): 59-61.

HeBARD, M.

1923. Studies in the Mantidae and Phasmidae of Panama (Orthoptera). Trans. Amer. Ent. Soc. 48: 327-361.

Hetrick, L. A.

1949. Field notes on a color variant of the two-striped walkingstick Anisomorpha buprestoides (Stoll). Proc. Entomol. Soc. Wash. 51: 103-104.

KEY, K. H. L.

1957. Kentromorphic phases in three species of Phasmatodea. Aust. J. Zool. 5: $247-284$.

KEY, J. H. L.

1970. Phasmatodea. In CSIRO, The Insects of Australia. Melbourne Univ. Press. Melbourne. pp. 348-359. 
KORBOOT, K.

1961. Observations on the life histories of Acrophylla tessellata Gray and Extatosoma tiaratum Macleay (Phasmida). Univ. of Queensland papers. 1: $161-169$.

LEA, F. E. S.

1916. Notes on the Lord Howe Island Phasma and on an associated longicorn beetle. Trans. Roy. Soc. South Aust. 40: 145-147.

Le Feuvre, W. P.

1939. A phasmid with spermatophore. Proc. Royal Ent. Soc. Lond. (A)14: 24. LEIGH, H. S.

1909. Preliminary account of the life history of the leaf insect Phyllium crurifolium Serville. Proc. Zool. Soc. Lond. 8: 103-113.

MOXEY, C. F.

1971. Notes on the Phasmatodea of the West Indies: two new genera. Psyche. 78: $67-83$.

PAine, R. W.

1968. Investigations for the biological control in Fiji of the coconut stick insect Graeffea crouanii (Le Guillon). Bull. Entom. Res. 57(4): 567-604.

PARKer, G. A.

1970. Sperm competition and its evolutionary consequences in the insects. Biol. Rev. 45: 525-567.

1974. Courtship persistence and female guarding as male time investment strategies. Behavior. 48: 157-184.

Potter, D. A., D. L. Wrensch, and D. E. Johnston.

1976. Aggression and mating success in male spider mites. Science. 193: $160-161$.

Rehn, J. A. G., AND J. W. H. Rehn.

1939. The Orthoptera of the Philippine Islands. Part I - Phasmatidea:Sp. Olriminae. Proc. Acad. Nat. Sci. Phil. 90: 389-487.

ROBINSON, M. H.

1965. The Javanese stick insect Orxines macklotti De Haan (Phasmatodea: Phasmidae). Entomol. Mon. Mag. 100: 253-259.

1968. The defensive behavior of the stick insect Oncotophasma martini (Griffin) (Orthoptera: Phasmatidae). Proc. Royal Ent. Soc. Lond. (A)43(10-12): 183-187.

SALMON, J. T.

1955. The genus Acanthoxyla (Phasmidae). Trans. Royal Soc. N. Zeal. 82(5): 1149-1156.

Severin, H. H. P.

1911. The life history of the walkingstick Diapheromera femorata. J. of Econ. Entomol. 4: 307-320.

SIVINSKI, J. M.

1977. Factors affecting mating duration in the walkingstick Diapheromera velii Walsh (Phamatodea: Heteronemiidae) M.S. Thesis Univ. of New Mexico. 
STOCKARD, C. R.

1908. Il Habits, reactions and mating instincts of the "walking stick": Aplopus mayeri. Papers from the Tortugas Lab. of the Carn. Inst. of Wash. 2: $43-59$.

STROHECKER, H. F.

1966. New Timema from Nevada and Arizona. The Pan-Pac. Entomol. 42: 25-26.

THORNHILL, R.

1976. Reproductive behavior of the lovebug, Plecia nearctica (Diptera: Bibionidae). Ann. Ent. Soc. Amer. 69(5): 843-847.

TRIVERS, R. L.

1972. Parental investment and sexual selection. In P. Campbell (ed.), Sexual selection and the descent of man, 1871-1971. Aldine-Atherton, Chicago, pp. 136-179.

UVAROV, B.

1966. Grasshoppers and locusts: A handbook of general acridology, vol. 1, 481 pp. Cambridge University Press.

WEGNER, A. M. R.

1955. Biological notes on Megacrania wegneri Willemse and $M$. alpheus Westwood (Orthoptera, Phasmidae). Treubia 23(1): 47-52.

Wilkins, O. P., And O. P. Breland.

1951. Notes on the giant walking stick Megaphasma dentricrus (Stal) (Orthoptera: Phasmatidae). The Texas J. of Sci. 2: 305-310. 

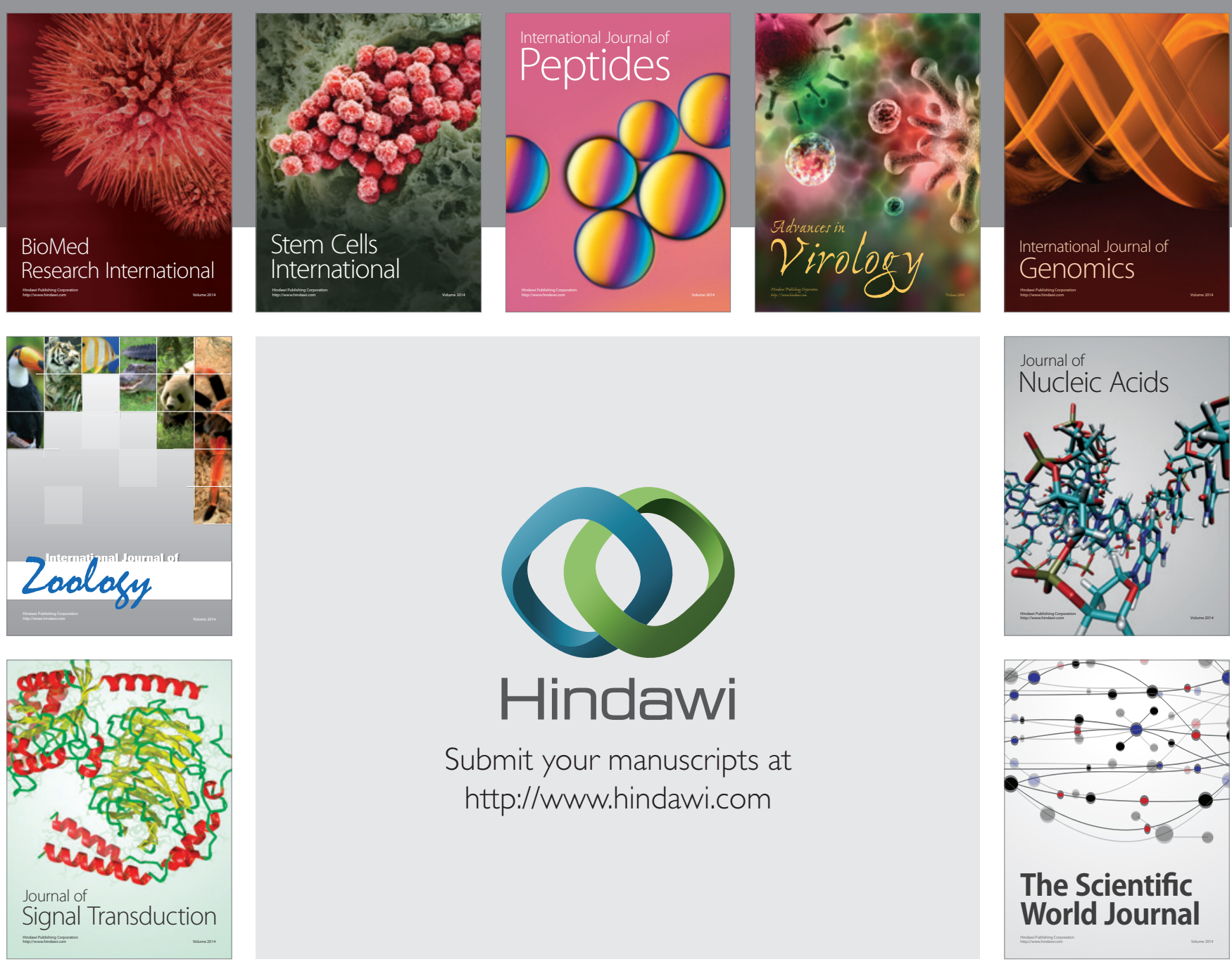

Submit your manuscripts at

http://www.hindawi.com
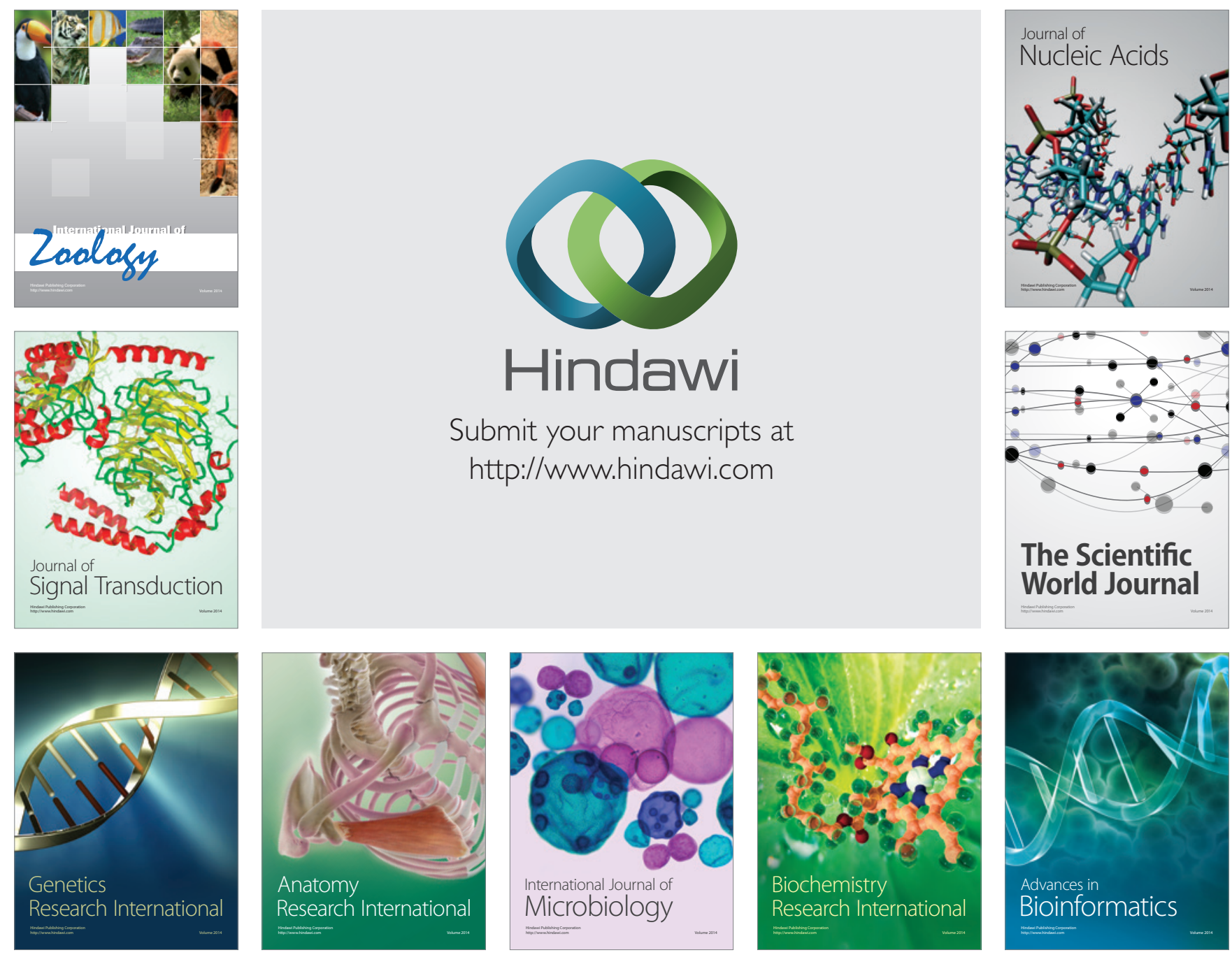

The Scientific World Journal
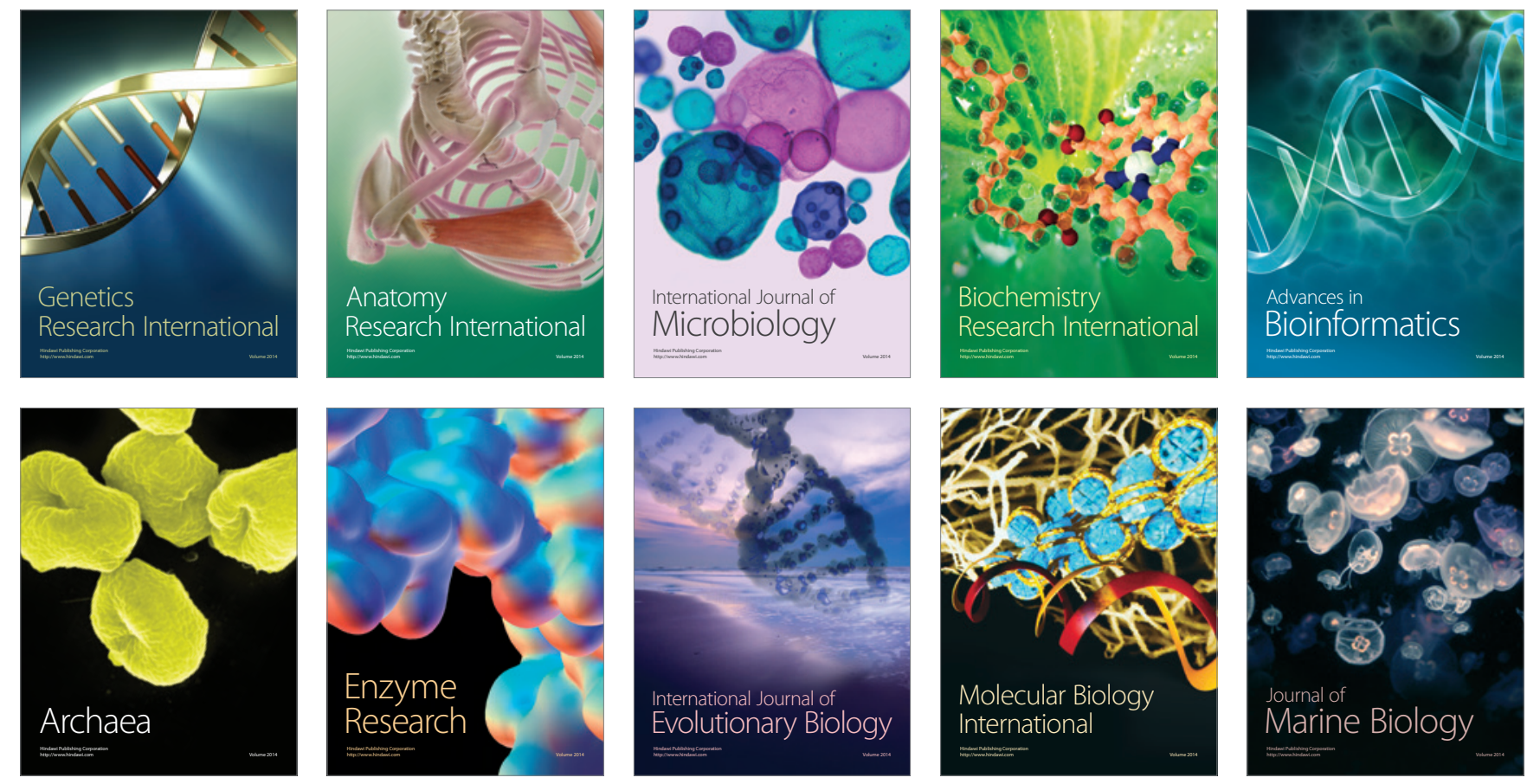